\title{
JUVENTUDES INDÍGENAS: ENTRE LAS MARCAS ÉTNICO-RURALES Y NUEVAS ADSCRIPCIONES URBANAS EN LA UNIVERSIDAD
}

Indigenous Youth: between rural-ethnic markers and new urban affiliations in the university

\section{Gabriela Czarny Krischkautzky \\ gacza_2006@yahoo.com.mx}

Universidad Pedagógica Nacional, Ajusco, Ciudad de México.

RESUMEN: El trabajo presenta resultados de investigaciones realizadas sobre y con jóvenes indígenas en un programa conocido como Licenciatura en Educación Indígena (LEI) que funciona en la Universidad Pedagógica Nacional (UPN), Ajusco, en la Ciudad de México. Se problematizan las imágenes arraigadas sobre cómo se conceptualizan, en este caso, a los jóvenes indígenas. Entre estos aspectos se confronta a la noción de migración indígena interna, y las experiencias contemporáneas de estas juventudes quienes para las políticas educativas y diversos sectores de la sociedad son vistos aún bajo la concepción de lo indígena y su base rural, lo que naturaliza identidades marcadas por hablar la lengua indígena, vestir de modo tradicional, entre otras. El texto muestra que todavía permanece el sesgo de la relación rural-urbano como frontera que busca establecer diferencias que se han utilizado para racializar, y al mismo tiempo da cuenta de los complejos y variados procesos socioculturales que viven las juventudes indígenas en una experiencia universitaria.

Palabras clave: Jóvenes, indígenas, educación superior, visibilidad, indígenas urbanos, México.

ABSTRACT: This paper presents the results of research about and with young indigenous people enrolled in the program Licenciatura en Educación Indigena (LEI) at the Universidad Pedagógica Nacional (UPN), Ajusco, Mexico 
City. The program problematizes the ingrained images of how indigenous young people are conceptualized. Among these aspects, the paper deals with internal indigenous migration and the contemporary experiences of these young people who are still regarded by the education system and many sectors of society within the concept of indigenous framework and its rural bases, which naturalizes identities markers such as speaking indigenous languages or wearing traditional clothes, among others. The paper shows that the biased rural-urban relationship still remains as a border that seeks to establish differences that have been used to racialize, and at the same time describes the varied and complex sociocultural processes experienced by indigenous young people at university.

KeYwords: Youth, indigenous, higher education, visibility, urban indigenous, Mexico.

\section{Introducción}

$\mathrm{E}$ s una tarea poco convincente seguir definiendo a las juventudes indígenas contemporáneas del mismo modo que la antropología de los años cincuenta en México definió a los indígenas y sus procesos culturales, en el marco de concepciones auto-contenidas y arraigadas a elementos rurales, así como a la definición de campesinos. Lo anterior se sostiene si consideramos que la globalización y los procesos de neoliberalismo han impactado en los pueblos, acentuando conflictos y divisiones en las comunidades, procesos que los han ubicado frente a retos multifacéticos que vienen asumiendo de diversos modos. Al mismo tiempo, nuevas perspectivas han entrado al campo de investigación, las cuales permitieron tanto la crítica de la antropología por su vinculación con el colonialismo como los abordajes multifocales que favorecen la irrupción de discursos otros, más allá de visiones homogéneas y certeras.

Definir, ubicar, comprender... a los jóvenes indígenas en el marco de procesos formativos universitarios, en un programa que se denomina Licenciatura en Educación Indígena (LEI), del que soy docente, implica no sólo reconocer 
las incidencias conceptuales y metodológicas presentes en el mismo campo de estudio socio-antropológico y educativo, sino también las derivaciones que las propias lentes pueden generar al definir y categorizar procesos culturales e identitarios de juventudes que acceden de manera desigual a la educación superior en México. El hecho de que muchos de los jóvenes procedan de contextos urbanos, porque han salido de sus comunidades de origen siendo pequeños, hace que desde las visiones oficiales y partes de la sociedad, los consideren como no indígenas. La imagen de pertenencia étnica por vivir en una comunidad reconocida en el discurso oficial como regiones indígenas y rurales, así como hablar una lengua indígena, sigue marcando destinos desde "arriba".

En este texto presentaré algunas tensiones y concepciones que siguen operando como dicotomías en el debate de lo que se ubica en el campo de políticas públicas para indígenas en la educación superior, y algunas de las narrativas de juventudes indígenas, que muestran un escenario polifacético, tal vez, reflejo de la vivencia y experiencia de muchas juventudes más allá de la marca étnica. Para ello, me baso en investigaciones que desarrollo con jóvenes indígenas en la educación superior, particularmente en torno a la experiencia de estas juventudes en un programa educativo que funciona en la Universidad Pedagógica Nacional (UPN), Ajusco, conocido como LEI, en la Ciudad de México. ${ }^{1}$

\section{Sobre la dicotomía rural-urbano para abordar procesos socioculturales y étnicos}

La antropología en México ha representado uno de los principales discursos que dieron visibilidad y nombraron en el escenario de la moderna nación independiente del siglo XIX y principios del xx, a los que denominamos indígenas, cuyos destinos manifiestos en diversos pueblos y comunidades han sido imaginados bajo esta categoría genérica.

1. Proyectos: Significados escolares en la Educación Superior (2010-12) y Formadores de profesionales de y para la educación indígenas (2017-18), UPN, Ajusco. 
Reconstruir la conformación de este campo disciplinario, centrado en el modo en que fueron definidas estas comunidades, no es tema de este texto, sin embargo es necesario señalar algunas de las posiciones conceptuales que marcaron el análisis del mundo indígena -desde inicios del siglo $\mathrm{xx}$ - como campesinos y, a través de ello, como culturas arraigadas en lo rural.

Como señala De la Peña (2016) -investigador de estos procesos y de la conformación del campo de la antropología mexicana-, con la influencia de la Escuela de Chicago se fue dibujando una antropología urbana que aportó conocimientos a otros procesos del mundo indígena y también sobre la nación. Este autor indica que esas investigaciones han contribuido a desmontar las dicotomías rural vs. urbano; tradición vs. modernidad; local vs. global, que caracterizaron a gran parte de los estudios y visiones sobre las comunidades indígenas como conglomerados cerrados, autosuficientes y como unidades compactas culturalmente. A modo de ubicar estudios centrales del campo que marcaron este debate y la comprensión en toda la región, citando a De la Peña:

Redfield (1940) mostró las transformaciones de los asentamientos humanos de la región maya de Yucatán por la penetración de la cultura urbana. Wolf(1956: 1065) sostuvo que "las comunidades no debían verse como sistemas autocontenidos e integrados [sino como] las terminaciones de una red de relaciones grupales [que incluyen ciudades]". Para el caso de las comunidades indígenas, Aguirre Beltrán (1958) propuso que esas relaciones grupales se constituían en el marco de un sistema regional de dominio en el que las elites urbanas mediaban y limitaban la acción del Estado y la operación del mercado: un tipo particular de sistema regional, operado desde la ciudad, generador de una economía pre-capitalista que frenaba la aculturación y propiciaba la reproducción de las diferencias étnicas y estamentales. En todos estos enunciados, si bien se afirmó la interdependencia de la ciudad y el campo, se supuso al mismo tiempo una separación física entre los indígenas rurales y los mestizos o blancos urbanos, que correspondía asimismo a una dualidad económica, política y cultural. En Yucatán, Redfield y sus colaboradores reconocieron la existencia de migrantes del campo a la ciudad de Mérida, pero postularon que, al cambiar de residencia, los indígenas mayas perdían su adscripción étnica (Hansen y Bastarrechea, 1984). En contraste, las pesquisas realizadas en Oaxaca por Covarrubias (1946) y por Malinowski y De la Fuente (1957) retrataron ciudades donde los indígenas residentes -zapotecas en particular- tenían una presencia protagónica en los mercados. Estas investigaciones desmintieron el supuesto de que la persistencia del mundo indígena 
era una función de su confinamiento en poblados rurales sujetos a un dominio agrario de índole pre-capitalista. A pesar de ello, la atención de la mayoría de los antropólogos mexicanos y mexicanistas continuó centrada en los indígenas rurales hasta la década de 1960 (Kemper y Royce, 1983) (De la Peña, 2017, p. 178).

Continuando con los procesos señalados en la antropología mexicana, entre los primeros trabajos de los años setenta, los de Lourdes Arizpe mostraron la presencia indígena en las ciudades generando "cierta" visibilización de estos pueblos. En éstos, se acuña el concepto de migración interna indígena, a través de la que se puso la observación en las mujeres indígenas que aparecían vendiendo chicles, dulces y artesanías en las esquinas y en diferentes zonas de la Ciudad de México. Su estudio sobre "las Marías", denominación genérica dada a las mujeres mazahuas que con sus ropas tradicionales, lengua originaria y la venta de productos artesanales, "tipificaron" una imagen de los indígenas, en momentos de fuertes movimientos del campo a las ciudades en un México que abandonaba la economía de las zonas rurales en búsqueda de un desarrollo industrial. Sin embargo, es hasta los años noventa que el tema de la presencia indígena en las ciudades y la multiplicidad de situaciones y procesos culturales e identitarios comienza ha adquirir mayor presencia en la investigación social y educativa.

No obstante, ese concepto de migración interna muy ligado a comunidades indígenas que salen de sus pueblos y regiones de origen dentro de México y que buscan asentarse en diversas ciudades (de distintos tamaños) en todo el país, ha marcado un modo de mirar la relación rural-urbano y en este tema, al etiquetarlo además a un componente étnico, la identidad indígena parece irremediablemente pensada sólo en torno de un sujeto campesino.

En primer lugar llamar migrante a los sujetos y comunidades indígenas que salen por diversas razones -económicas, políticas, religiosas y de violencia de todo tipo- de sus comunidades, mantiene una carga de extranjeridad. En este sentido, trabajos de investigación ya han señalado que los indígenas que se trasladan a las ciudades son tratados como extranjeros o como no pertenecientes a este país (Oehmichen, 2005; Martínez, 2014).

Asimismo, diversas organizaciones indígenas asentadas en las ciudades han reclamado que no son migrantes, sino que reivindican sus derechos a ser 
reconocidos como indígenas y al mismo tiempo como ciudadanos mexicanos. En este señalamiento, el hecho de cambiar de residencia y moverse a lo largo del territorio nacional no debería implicar ser considerados como migrantes.

Tratar a los indígenas bajo esa carga de extranjeridad remite a la historia profunda de colonización y racismo que se ha mantenido desde la Colonia, aunque con rasgos diferentes con la creación de las naciones independientes desde el siglo XIX. Esas concepciones que desde la academia y desde los discursos oficiales se han ido configurando, en donde "lo indígena" sigue ligado a imágenes de comunidades rurales y alejadas no sólo de los escenarios urbanos, sino de lo que "debe ser un sujeto moderno", atraviesa y refuerza oposiciones y dualidades como la de sujeto urbano o sujeto rural, y toda la connotación adjetivante que profundiza dicotomías. Como lo señalan Czarny y Martínez:

Es la relación campo-ciudad, caracterización dual que estableció diferencias de poder a través de resaltar identidades culturales en oposición, acentuando la idea de progreso y sujetos civilizados por vivir en ciudades versus sujetos atrasados y bárbaros, definidos así por ser y reconocerse como campesinos. Si para ser ciudadano en las nacientes naciones del siglo XIX había que ser exponente de un modelo de civilización, inspirado en una noción de ciudad eurocéntrica y un modo de vida, entonces los que vivían fuera de ella, ¿qué serían? (Czarny y Martínez, 2013, p. 171).

Si bien la noción de ciudad se ha ido modificando, la tendencia que aún sigue predominando para la definición en México de la urbe, es utilizar el aspecto demográfico. ${ }^{2}$ Aunque hoy encontramos indígenas viviendo en ciudades de distintos tamaños del país, lo que permanece es la imagen de que los indios "puros" sólo pueden vivir en comunidades en zonas rurales.

Resaltar las oposiciones señaladas anteriormente -campo vs. ciudad y todos los adjetivos que a ello se le agregan casi como un campo semántico

2. Cada país fija un volumen de población mínimo para considerar a un núcleo de población como ciudad. Entre las fuentes que consideran el tema en México señalan que la mitad de la población indígena reside en localidades rurales de menos de 2500 habitantes. Aunque tradicionalmente esta población se ha asociado al ámbito rural, los datos en UNICEF-INEE, 2014, muestran que 50\% de los indígenas -a nivel nacional- se localizan en localidades urbanas y semiurbanas, e incluso $18.6 \%$ reside en ciudades y zonas metropolitanas de más de 100000 habitantes. 
en contextos de fuertes desigualdades y racismos-, refleja el sesgo sobre una posición que refuerza la discriminación y justifica, en nombre de la diferencia, políticas de desigualdad que buscando "atender" lo indígena mantienen las inequidades en distintos niveles.

\section{Investigaciones recientes sobre indígenas en contextos urbanos}

En los últimos 20 años, comenzaron a investigarse procesos socio-territoriales y socioculturales de comunidades y pueblos indígenas en contextos urbanos. Entre los trabajos que desmontan no sólo la hegemónica noción de ciudad sino los diversos modos de asentamientos de comunidades y pueblos en las ciudades, se ubican los trabajos de Portal (2011) sobre los pueblos originarios del Anahuac que habitan lo que se denomina Ciudad de México y zona metropolitana. Esos dejan al descubierto procesos de adscripción y membresías comunitarias que involucran elementos diversos -materiales, territoriales y simbólicos- pero que conforman perfiles socio-cumunitarios e identidades, en los transformados y conflictivos espacios urbanos. También, los estudios de Martínez Casas y Rojas (2006) sobre procesos de invisibilización indígena en contextos urbanos en la ciudad de Guadalajara, así como la resignificación de las identidades étnicas de adolescentes y jóvenes indígenas en los nuevos escenarios de vida; y los trabajos de Czarny $(2008 ; 2017)$ que señalan las conflictivas y discriminatorias experiencias que viven los indígenas en las ciudades y en las escuelas primarias generales en el contexto de la Ciudad de México, además de poner en escena los debates inconclusos sobre ciudadanía(s) para repensar sociedades denominadas pluriculturales.

Sin embargo, la ausencia de reconocimiento sobre comunidades indígenas en contextos urbanos y en el sistema educativo general público, aún es un aspecto pendiente. En este sentido, el que no se identifique y silencie, por ejemplo, la presencia de niños y jóvenes indígenas en diversos niveles del sistema escolar en contextos urbanos, refuerza las hipótesis que venimos señalando en estudios anteriores. Los indígenas en procesos de escolarización en ciudades son invisibilizados debido a diferentes razones, entre ellas: las concepciones sobre lo indígena que marcan las ideologías del México 
llamado mestizo, en el que los indios siguen siéndolo sólo si hablan alguna de las lenguas indígenas; por intensos procesos de redefinición identitaria en los mismos sujetos y comunidades, la que está mediada por la pertenencia territorial y los efectos de la discriminación; por la carencia de diagnósticos sociolingüísticos y socioculturales en las escuelas, así como el diseño y aplicación de instrumentos cuantitativos y cualitativos que den cuenta de la composición multiétnica de nuestra sociedad (Czarny, 2008; Martínez C. y Rojas, 2006; Martínez, 2014).

En fechas recientes, las instituciones encargadas de las políticas dirigidas a pueblos indígenas comenzaron a identificar la complejidad de procesos de las comunidades indígenas que dejan sus lugares de origen, reconociendo diversas formas de asentamientos en las ciudades. Así, en 2011, la Comisión para el Desarrollo de los Pueblos Indígenas (CDI) impulsó un diagnóstico sobre la población indígena en zonas urbanas para la elaboración de una propuesta para el diseño de un programa de atención a este segmento de la población (CDI, 2011). Señala que plantear la identificación de las comunidades indígenas como elemento necesario para el reconocimiento y ejercicio de los derechos colectivos previstos en el artículo $2^{\circ}$ de la Constitución Política de los Estados Unidos Mexicanos, es parte de las acciones que impulsan algunas instancias federales y estatales (CDI, 2011).

El diagnóstico al que se hace referencia menciona que las ciudades mexicanas se han convertido en espacios multiculturales gracias a la creciente presencia de indígenas, pero también destaca la discriminación que viven los sujetos y las comunidades; la precaria condición de inserción a lo "urbano"; el debilitamiento de procesos culturales; y las dificultades que este sector tiene para acceder a diferentes bienes y servicios que brindan gobiernos locales. Indudablemente, estos diagnósticos son de mucha importancia pero, al mismo tiempo, mantienen la idea de que las políticas que se diseñen deben “atender a los indígenas". En este sentido, el tema indígena mantiene, desde inicios del siglo $\mathrm{XX}$, una perspectiva en la que los pueblos y comunidades son abordados como sujetos de interés para las políticas públicas, y no como sujetos de derecho (Díaz, 1998), aunque a la fecha el discurso oficial haya cambiado en este aspecto. Como se aprecia, desde las políticas públicas mencionadas se mantiene una perspectiva que considera que los indígenas en los 
contextos urbanos "debilitan o pierden su cultura", aspecto que corresponde a las tendencias arraigadas desde visiones antropológicas que entienden a la cultura como ente estático, y en la medida que éste se dinamiza tiende a desaparecer como rasgo "original".

Es interesante resaltar cómo los investigadores indígenas analizan lo que se encubre detrás de esas visiones oficiales y de ciertas perspectivas académicas que siguen oponiendo lo rural vs. lo urbano, como escenario para definir procesos culturales de los pueblos. Por ejemplo, Lucas (2016), proveniente del Estado de Veracruz desde muy temprana edad, quien ha desarrollado toda su escolarización en la Ciudad de México, señala la discriminación que mantiene el discurso oficial, al seguir tratando a los indios que viven en las ciudades como migrantes, y cuestiona este concepto al igual que el de avecindados o residentes que suelen darse a los indígenas que dejan sus comunidades de origen y se asientan en otros escenarios urbanos. Domínguez, en su investigación sobre indios urbanos en la ciudad de Guadalajara (2013), documenta procesos personales y familiares de lo que es ser parte de una comunidad zoque, originarios del estado de Chiapas, que se han trasladado a su muevo lugar de residencia, y las formas en que la sociedad hegemónica va marcando a los propios modos de auto-definirse en tanto joven indígena zoque, y los complejos procesos de identificación con la sociedad mayoritaria de ese contexto.

Estos estudios han señalado que el hecho de haber accedido a distintos niveles escolares hasta el posgrado en las ciudades, no borra las fronteras -producto de racismo explícito o encubierto-, emocionales, materiales y simbólicas que deben enfrentar los que ahora pueden ser llamados indígenas urbanos.

\section{La invisibilidad de los jóvenes indígenas en la educación superior}

Las demandas indígenas por mayor acceso a la educación superior se han convertido en un tema importante en el actual debate latinoamericano, pues representa para algunos una herramienta hacia la construcción de proyectos 
de autonomía y de mejora en las condiciones de vida individuales y colectivas. Aunque la educación superior ha sido tradicionalmente un espacio de exclusión y de invisibilización de los saberes y prácticas de los pueblos indígenas, una serie de coyunturas regionales, nacionales e internacionales han provocado un cambio en este campo.

La investigación en estas áreas ha avanzado en la documentación y el análisis de la implementación de algunos de los programas en el nivel superior que han aplicado políticas de acción afirmativa, que en México han sido de base étnica, tanto en las universidades convencionales como en las universidades interculturales (Mato, 2009; Mateos et al., 2013). La distinción entre universidades convencionales o interculturales es una noción que acuñó Mato (2009) en el marco de los estudios que comienzan sobre finales del siglo XX en la región sur y centro de América, y que han venido identificando diversas experiencias institucionales en este nivel, dirigidas a las comunidades indígenas. Las universidades convencionales incluyen programas que se dirigen a población indígena dentro de las estructuras tradicionales que tienen las universidades públicas o privadas, generalmente en zonas urbanas; las interculturales en México se crearon en el año 2004, en zonas cercanas o en regiones rurales y consideradas como de alta población indígena, con un modelo específico en el tipo de carreras y dirigidas a esta población (CGEIB, 2018).

La acción afirmativa como estrategia en la educación superior llegó a México hacia principios del año $2000 \mathrm{y}$, principalmente a través del componente étnico, buscó ampliar y dar acceso a los jóvenes indígenas a la educación superior en programas diversos de licenciaturas y en posgrados. Entre los aspectos que estas acciones consideran como antecedente para la asignación de un apoyo económico se encuentra el de que sean miembros y hablantes (en muchos casos) de alguna lengua indígena, además de que deben tener tutorías específicas y apoyo académico en el entendido de que las escolaridades previas de estos jóvenes han sido desiguales e inequitativas en términos de calidad. Esto último remite a varios procesos, entre ellos, las 
opciones escolares paralelas y compensatorias a las que han debido concurrir, oferta vigente en las comunidades rurales e indígenas (Czarny, 2012). ${ }^{3}$

Sin embargo, desde finales de los años setenta, en el país, se han creado programas para la formación de profesionales indígenas, inicialmente en el campo de la lingüística y en la educación (Gigante, 1994; Rebolledo, 2015; González, 2017), impulsados por las organizaciones indígenas con el apoyo de académicos. Generalmente, estos programas han considerado un perfil de ingreso que hace puntuación en el hecho de pertenecer a una comunidad o pueblo indígena, y hablar alguna lengua originaria, hoy consideradas lenguas nacionales.

En este escenario, la LEI se crea en 1982 y ha sido uno de los primeros programas en la región para la formación de profesionales de la educación indígena. Surge en la Unidad Ajusco de la UPN, en la Ciudad de México, con una modalidad escolarizada. Su objetivo principal fue profesionalizar a directivos y docentes de educación indígena que estaban frente a escuelas de educación indígena y que no contaban con formación terciaria ni universitaria. Este programa no es de formación inicial de docentes, ${ }^{4}$ sino una propuesta curricular destinada a formar profesionales y técnicos de diversos campos y ámbitos de y para la educación indígena.

Con el último cambio curricular, Plan de estudios 2011, se impulsa la formación profesional en áreas como la educación bilingüe, el desarrollo comunitario y la formación docente, aspectos que orientan hacia un perfil de egreso que pretende abrir los ámbitos profesionales con la diversidad existente en la actual población indígena de nuestro país, tanto en zonas rurales y urbanas como en los distintos niveles del sistema educativo al que llegan niñas, niños, jóvenes y adultos provenientes de diferentes comunidades y pueblos indígenas.

Con el paso del tiempo, el perfil de los ingresantes a este programa ha cambiado. En la actualidad, después del cambio de tres planes de estudio

3. Nos referimos a que en la búsqueda por la cobertura escolar en educación básica, el sistema creció de manera desigual, no sólo en términos materiales (infraestructura escolar), sino en las políticas e instituciones encargadas para la formación de docentes y propuestas educativas.

4. La formación inicial corresponde a la que se oferta a cargo de las escuelas normales. 
-a diferencia de las primeras generaciones conformadas por profesores de educación indígena, en su mayoría varones mayores de 30 años de edad y con diferentes niveles de liderazgo comunitario-, los estudiantes de la LEI tienen otros rasgos y demandas. La mayoría de los alumnos son jóvenes con estudios de bachillerato que buscan un espacio en el ámbito de la educación superior, siendo un alto porcentaje de mujeres. Apoyados, muchos de ellos, económicamente por sus familias y sin experiencia docente; otros, para poder sostener su estancia en la Ciudad de México y concluir sus estudios, se incorporan al mercado laboral, principalmente, en el sector de servicios. Entre los jóvenes de estas generaciones algunos hablan y escriben una lengua originaria, además del español; y otros ya no hablan las lenguas indígenas de sus padres o abuelos y es el español la principal forma de comunicación en todos sus procesos sociales.

Este programa opera en la Universidad, en donde además se ofertan carreas como Pedagogía, Psicología, Sociología de la Educación, Administración Educativa y programas de posgrado en Educación. En este sentido, la marca de lo étnico se visibiliza sólo en el programa de la LEI. Sin embargo, es sabido que en las otras carreras también existen jóvenes indígenas, procedentes de diversas comunidades, algunos ya nacidos en la Ciudad de México u otras. El hecho de asumir una marcación étnica y con ello ingresar a un programa que se denomina de educación indígena; o el querer ingresar a un programa que se oferta a todos los jóvenes más allá de una etiqueta que remarca lo étnico, forma parte de las tensiones, dilemas y confrontaciones históricas que las comunidades y juventudes indígenas han tenido que afrontar.

Si bien, para un sector de los estudiantes el hecho de haber ingresado a la LEI ha resultado de las únicas opciones en educación superior-aspecto que remarca procesos de inequidad, desigualdad y racismos-, en general estar en el programa ha permitido revalorizar, reivindicar y fortalecer sus adscripciones e identificaciones comunitarias, con diversos acentos. No obstante, la aún presente distinción entre programa para indígenas -en universidades convencionales o interculturales-, resultan de las fronteras que siguen resaltando especificidades culturales y lingüísticas de los sujetos, que más allá de esa condición se busca mantener como esencias, aunque las realidades de las juventudes de cuenta de otros procesos identitarios, lingüísticos y culturales 
multifacéticos. Esto último no concluye con la idea que por esa multiplicidad de procesos los jóvenes no se reconozcan y sean activos miembros de sus comunidades; por el contrario y como veremos, la membresía y adscripción a las comunidades se construye de diversos modos.

\section{Estudiantes indígenas entre fronteras étnico-rurales y urbanas}

Las experiencias de los jóvenes indígenas en el marco del programa educativo de la LEI-UPN, podría ser correlato de otras experiencias de juventudes indígenas en la educación superior. En este apartado haré referencia a los modos en que las marcas de lo rural y lo urbano, juegan de distinto modo entre las juventudes indígenas para afrontar la vida escolar urbana, al mismo tiempo que reconocerse como miembros de pueblos originarios.

Un sector de los estudiantes de este programa educativo proceden de sus comunidades de origen ubicadas en zonas consideradas "rurales", tanto en la marcación que desde las instancias oficiales se hace de este tipo de poblado, pero también en la forma en cómo los jóvenes indican que provienen "del pueblo". Así la idea de venir "del pueblo", o de "la ciudad", parece formar parte de un escenario que naturaliza identidades. En este sentido, no se trata de negar que los contextos de crianza familiar y comunitarios, resultan marcas en los procesos de socialización y, con ello, los modos de aprender a mirar y a entender no sólo lo "local" -el lugar de origen- sino lo global -lo que está afuera-. No obstante, la multiplicidad de formas en que esas "marcas" se configuran y son utilizadas por los jóvenes es lo que busco resaltar.

Como parte de las etiquetas que suelen utilizarse en los discursos oficiales, en este caso sobre quién es indígena y quién no, la oposición ruralurbano mantiene un sesgo que parece definir procesos culturales que no se interrelacionarían y que guardarían "especificidades" en los sujetos. Sobre ello hay que señalar que la experiencia de "salir del pueblo", para un amplio de sector de los jóvenes indígenas, está presente desde temprana edad porque en gran parte de las comunidades no cuentan con servicios escolares para la educación media ni superior, aspecto que obliga a que "migren" a cabeceras municipales en ocasiones cercanas y a diversas ciudades. En este sentido, la 
experiencia de salir del pueblo y "adaptarse" a otros ámbitos siendo adolescentes y jóvenes, forma para de las trayectorias escolares de éstos.

Sin embargo es interesante identificar en los relatos de varios jóvenes estudiantes de la LEI -tanto hombres y mujeres- que incluso habiendo experimentado la salida de sus comunidades con anterioridad, el hecho de llegar a la Ciudad de México para estudiar en la Universidad tiene otras implicaciones en términos de la experiencia de sentirse "en situación de extrañeza", y sobre ello han comentado:

... venir a la Ciudad de México ha sido totalmente diferente, desde la comida, hasta moverse (el metro, los camiones), el hecho de conocer a estudiantes que también son de otros pueblos, y que hablan alguna lengua indígena, eso yo no lo sabía hasta que entré a la LEI. ${ }^{5}$

La extrañeza hace referencia, en este caso, a ciertos hábitos alimenticios, por ejemplo, "en el pueblo se come mejor, la comida y el agua saben mejor, aquí comen raro"; es decir, desde cosas básicas como la comida y el agua se adquiere conciencia de prácticas culturales que se valoran en la extra-comunalidad. Estos procesos de revaloración de lo propio y la demarcación de fronteras sociales, étnicas e identitarias, -ampliamente estudiados por la antropología, los estudios culturales y de migración-, constituyen experiencias que contribuyen a las nuevas reformulaciones y procesos de subjeti$\operatorname{vidad}(\mathrm{es})$.

En otro sentido, la extrañeza también refiere, aunque entendido más como "descubrimiento", al hecho de encontrarse con jóvenes pertenecientes a otras comunidades y pueblos indígenas, hablantes o no de las lenguas originarias, aspecto que experimentan por primera vez cuando llegan al programa educativo. Este descubrir que "somos muchos los que hablamos otras lenguas y venimos de comunidades...", da cuenta de la percepción que los jóvenes tienen sobre quiénes son indígenas -en tanto grupo minoritario-, y que en el encuentro con las diversidades presentes en el aula, se transforma esa idea pero en un descubrimiento con marcas de incidencia política, al redefinir que más bien los pueblos indígenas han sido "minorizados".

5. Testimonio de una estudiante del $6^{\circ}$ semestre, LEI, generación 2016-19, sin embargo es un comentario recurrente en un amplio sector de los estudiantes. 
El soporte familiar y comunitario, para un amplio sector de los jóvenes que llegan a estudiar a la LEI en la UPN, es referencial también para afrontar la "extrañeza" de estar en una megaciudad como la de México. Como diversos trabajos sobre migración indígena lo han señalado, las redes de paisanaje o amistad son centrales en los nuevos enclaves urbanos a los que llegan para solventar situaciones emocionales, sociales y de subsistencia frente a diversos modos de discriminación (Martínez y Rojas, 2006; Domínguez, 2013). En este caso, un sector del estudiantado cuenta con apoyos familiares y redes de compadres que llegaron tiempo atrás a vivir a la ciudad; otros van gestando nuevas relaciones en sus procesos universitarios, con quienes se organizan para compartir casa y diversas experiencias urbanas.

Otro sector de estudiantes son jóvenes que viven la Ciudad de México y su zona conurbada, y que han ya transcurrido su escolarización en ella porque sus padres se trasladaron de las comunidades en búsqueda de mejores condiciones de trabajo y estudio. Para este grupo, la extrañeza no se da en relación con los hábitos de la vida urbana -comida, transporte, entre otros-, sino por el re-descubrimiento de sus propios orígenes y la recuperación de una historia en muchos casos silenciada por sus padres, como efecto de la discriminación.

\section{Conclusiones}

A través del texto se advierten varios aspectos, entre ellos, la continuidad en el uso de categorías dicotómicas que se adscriben a los jóvenes indígenas por ser rurales o urbanos, y las derivaciones en términos de esencialismos a lo que ello conduce. Al mismo tiempo, la importancia de visibilizar la existencia de estas marcas "étnicas" en los jóvenes, en países que constitucionalmente se denominan pluriculturales y multilingües, proceso al que se le van acuñando otros términos, como el de indígenas urbanos. No obstante, la paradoja es que para "hacer visible" al "otro" haya que construir nuevas categorías que logren mover las imágenes esencializadas sobre las culturas e identidades, en este caso, de los indígenas.

En este sentido, el trabajo sobre las presencia indígena -impulsado por parte de los jóvenes como de los académicos que tratan el tema-, requiere 
de estrategias para des-naturalizar lo arraigado en el imaginario de quién es indio (puro) y quién no. Esas imágenes y creencias son parte de una estructura ideológica impuesta, utilizada para racializar, entendiendo por ello al proceso histórico de racismo estructural que forma un sistema social y que penetra todas las esferas de la vida política, económica y social (Bonilla-Silva, 1997, en Hellebrandová, 2014).

Más allá de la marcación de las juventudes como "rurales" o "urbanas", la investigación muestra las diversas formas de construir un relato propio bajo el cual el concepto genérico de jóvenes indígenas se condensa.

La experiencia en la LEI moviliza a nuevas reflexiones y, tal vez, la más fuerte es la de comenzar a compartir con otros jóvenes -no sólo de la LEI sino de las otras carreras de la UPN-, lo que algunos estudios denominan culturas juveniles. Sin el afán de mostrar en este texto que ello suceda con los jóvenes indígenas en la universidad, se pueden advertir algunos de los caminos que recorren - no sin el peso de la discriminación en muchos casos-, que los arrojan a otras situaciones de confrontación, identificación, resistencia. A través de éstas, se vislumbran prácticas posibles de un "común" más amplio -los jóvenes universitarios en la Ciudad de México-, al mismo tiempo que mantienen lealtades comunitarias que les recuerdan quiénes son y porqué estudiar. 


\section{Referencias}

ArizPe, L. (1978). Migración, etnicismo y cambio económico. Un estudio sobre migrantes campesinos a la ciudad de México. México: El Colegio de México.

CDI (2011). Acciones del Gobierno Federal para el Desarrollo Integral de los Pueblos Indígenas. Informe 2011. México. Recuperado de https://www.gob.mx/cms/uploads/attachment/file/32223/cdi_informe_2011.pdf en diciembre de 2017.

CGEIB (2018). Universidades interculturales. Recuperado de http://eib.sep. gob.mx/universidades-interculturales

Czarny, G. (2008). Pasar por la escuela. Indígenas y procesos de escolaridad en la ciudad de México. Mexico. UPN.

Czarny, G. (2012). Jóvenes indígenas en la UPN. Relatos escolares desde la educación superior. México: UPN.

Czarny, G. (2017). Schooling processes and the Indigenous peoples in urban contexts in Mexico. En W. Pink y G. Noblit (eds.), Second international handbook of urban education. vol. 1 (pp. 487-504). Suiza: Springer.

Czarny, G. y Martínez, E. (2013). Escolarización indígena en contextos urbanos y de migración. En M. Bertely, G. Dietz y G. Díaz Tepepa (eds.), Multiculturalismo y educación 2002-2011 (pp. 253-282). México: COMIE.

Díaz Couder, E. (1998). Diversidad cultural y educación en Iberoamérica. Revista Iberoamericana de Educación, Educación, Lenguas y culturas (17), 11-30.

Domínguez, F. (2013). La comunidad transgredida. Los zoques en Guadalajara. México: Unidad de Apoyo a las Comunidades Indígenas-Universidad de Guadalajara.

Gigante, E. (1994). Formación de maestros para educación intercultural bilingüe. Reporte investigación. Fundación Sindicato Nacional de Trabajadores de la Educación-UNESCO-OREALC.

GonzÁLEz, E. (2017). Apropiaciones escolares en contextos etnopolíticos. Experiencias de egresados de la educación intercultural comunitaria ayuujk. México: Casa Chata-CIESAS.

Hellebrandová, K. (2014). El proceso de etno-racialización y resistencia en la era multicultural: ser negro en Bogotá. Universitas Humanísticas (77), 145-168, enero-junio.

INEE-UNICEF (2016). Panorama educativo de la población indígena 2015. 
México: autor. Recuperado de http://www.inee.edu.mx/images/ stories/2016/mesa-PEPI/PEPI en febrero 2018

LuCAs, L. (agosto de 2016). Población originaria en movimiento. La Jornada, Ojarasca, suplemento número 232, pp. 4-5. Recuperado de http:// issuu.com/lajornadaonline/docs/ojarasca_232 marzo 2018.

Martínez, E. (2014). Relaciones internétnicas de niños indígenas desde un contexto escolar urbano. En E. Martínez Buenabad (coord.), Repensar la educación desde la antropología: sujetos, contextos y procesos (pp.33-54). México: CIESAS-ICSyH.

Martínez Casas, R. y RoJas, A. (2006). Indígenas urbanos en Guadalajara: etnicidad y escuela en niños y jóvenes otomíes, mixtecos y purépechas. En El Triple desafío: Derechos, instituciones y políticas para la ciudad plural (pp.69-98). México: Universidad Autónoma de la Ciudad de México-Gobierno del Distrito Federal-Secretaría de Desarrollo Social.

Mateo, L., Mendoza, R. y Dietz, G. (2013). Diversidad e interculturalidad en la educación superior convencional. En M. Bertely, G. Dietz y G. Díaz Tepepa (eds.), Multiculturalismo y educación 2002-2011 (pp. 213-245). México: COMIE.

MATo, D. (coord.) (2009). Instituciones interculturales en educación superior en América Latina. Procesos de construcción, logros innovaciones y desafíos. Caracas, Venezuela: IESALC-UNESCO.

Oenmichen, C. (2005). Identidad, género y relaciones interétnicas. Mazahuas en la ciudad de México. México: UNAM.

Peña, G. DE la (2016). II Encuentro México-Brasileño de Antropología. Ciudades, diversidades y ciudadanías en la antropología mexicana. Desacatos (48), 177-191.

Portal, A. (2011). Pueblos urbanos: entorno conceptual y ruta metodológica. En L. Álvarez Enríquez (coord.), Pueblos urbanos identidad, ciudadanía y territorio en la Ciudad de México (pp.25-46). México: Porrúa-UNAM.

Rebolledo N. (2015). Contribuciones de la antropología a la educación indígena (1939-1969). En A. Medina Hernández y M. Rutsch (eds.), Senderos de la antropología: discusiones mesoamericanistas y reflexiones históricas (pp. 349-377). México: Instituto Nacional de Antropología e Historia-Instituto de Investigaciones Antropológicas-Universidad Nacional Autónoma de México. 